\title{
Electrical and Optical Characteristics of Copper Antimony Sulphide Thin Films Fabricated in Chemical Baths of Different Growth Media
}

\author{
Augustine Ike Onyia*, Mishark Nnamdi Nnabuchi, Abraham Iheanyichukwu Chima
}

Department of Industrial Physics, Enugu State University of Science and Technology, Enugu, Nigeria

Email address:

ikeaonyia@yahoo.com (A. I. Onyia)

${ }^{*}$ Corresponding author

\section{To cite this article:}

Augustine Ike Onyia, Mishark Nnamdi Nnabuchi, Abraham Iheanyichukwu Chima. Electrical and Optical Characteristics of Copper Antimony Sulphide Thin Films Fabricated in Chemical Baths of Different Growth Media. American Journal of Nanosciences.

Vol. 5, No. 1, 2020, pp. 1-5. doi: 10.11648/j.ajn.20200601.11

Received: April 14, 2020; Accepted: May 7, 2020; Published: May 28, 2020

\begin{abstract}
Chemical Bath Deposition Technique has been used to fabricate thin films of copper antimony sulphide in two different growth media: water and polyvinyl alcohol and the effects of these media on the electrical and optical properties of the $\mathrm{CuSbS}_{2}$ thin films studied. The technique required a liquid precursor; usually a solution of organic metallic powder dissolved in an organic solvent and kept in a reaction bath where reaction takes place. The precursor reaction chemicals used were copper chloride, antimony chloride and sodium thiosulphate and precipitations were on pre-cleaned borosilicate glass substrate at room temperature and $\mathrm{pH}$ of 9.1. Both deposits were subsequently similarly annealed for an hour each at a temperature of $250^{\circ} \mathrm{C}$ before testing the optical characteristics of both films using a UV-VIS-NIR $200-1100 \mathrm{~nm}$ range spectrophotometer and electrical characteristics, using a Quadpro four point probe. A proton induced Rutherford backscattering done on films detected thicknesses of films to be $545 \mathrm{~nm}$ and $514 \mathrm{~nm}$ for water and PVA bath deposits respectively. The thin film resistivities recorded were also $770 \Omega \mathrm{m}$ and $699 \Omega \mathrm{m}$ respectively. Absorbance, refractive indices, and other major optical parameters of the thin films varied differently with growth media in the infra red but remained fairly same in the visible and other higher frequency ranges.
\end{abstract}

Keywords: Chemical Baths, Thin Film, PVA Baths, Spectrophotometer

\section{Introduction}

Chemical bath deposition (CBD) technique has, in recent time, been the choice technique of fabricating size-reduced (nanosize) thin films of chalcogenides [1-4]. It is cheap, reproducible and generally accepted to be useful for large area and irregular thin surface applications [5]. The method relies on the fact that, without application of external fields, thin film (TF) can be grown on both metallic and non metallic substrates by dipping them into a suitable reaction baths that contain metallic salts and in a growth medium of either deionised water or polyvinyl alcohol (PVA). Extensive literature on size reduction effect is available [6-9]. CBD technique as well as some other techniques have been used to improve various chalcogenides, especially sulphides from the early binary TFs to the present frontier of ternary, quaternary and multinary devices, such as copper indium sulphide, that possess band gaps appropriate for solar light harvesting, photovoltaic properties, selective surfaces and other optoelectronic properties [10]. In this work, effort is concentrated on the growth of $\mathrm{CuSbS}_{2}$ TF. Any improvement in the fabrication of this semiconductor could replace the present usual usage of CIGS nanorods as flexible photodetector since antimony is far cheaper and indeed more abundant than indium, yet presents similar chemistry [11]. Some other techniques readily applicable for growing $\mathrm{CuSbS}_{2} \mathrm{TF}$ include: spray pyrolysis [12], and annealing stack $\mathrm{Sb}_{2} \mathrm{~S}_{3}-\mathrm{CuS}$ films freshly grown using chemical bath deposition technique [13]. In the CBD growths referred to herein, researchers have variously used either water or PVA as the growth bath medium even as the specific effects of either of the two growth media have scarcely been determined. A researcher 
has however previously examined such effects on the structural properties and elemental composition of $\mathrm{CuSbS}_{2}$ [14]. It is the expectation of this work to also study the effect of both media on the electrical and optical characteristics of CBD synthesized copper antimony sulphide thin film.

\section{Experimental Details}

Seven $\mathrm{ml}$ acetone $\left(\mathrm{CH}_{3} \mathrm{COCH}_{3}\right)$ was used to dissolve $1.2 \mathrm{~g}$ antimony chloride $\left(\mathrm{SbCl}_{3}\right)$ which was stirred into a beaker containing $7 \mathrm{ml}$ of $1.1 \mathrm{M}$ copper chloride $\left(\mathrm{CuCl}_{2}\right)$ and $12 \mathrm{ml}$ of $1.5 \mathrm{M}$ sodium thiosulphate $\left(\mathrm{Na}_{2} \mathrm{~S}_{2} \mathrm{O}_{3}\right)$. A vigorous magnetic stirrer was applied on the solution while $20 \mathrm{ml}$ of water was quickly introduced into the beaker. A precleaned plane boroscillicate glass slide meant to be the substrate was inserted down to the solution through a supporting piece of synthetic foam that rested on top of the beaker to also seal it off. The bath which had a pH of 9.1 was kept uninterrupted for 4.5 hours at room temperature after which the slide $(33 \mathrm{G})$ which was now covered with copper antimony sulphide thin film, was removed, rinsed in plenty of deionised water and drip dried in dust free environment. A similar growth exercise as above, was also carried out except that, instead of distilled water, polyvinyl alcohol was used and the slide was labeled $33 \mathrm{H}$. In both cases there was precipitation of $\mathrm{CuSbS}_{2}$ and this precipitation rate was slowed down by acetone complexant to ensure orderly growth. The $\mathrm{CuSbS}_{2}$ precipitates rather quickly formed as crystallite grains on the glass and these grains later developed into a continuous film layer after a reasonable dip period. The complexation caused a slow release of $\mathrm{Sb}$ ions as follows:

$$
\begin{gathered}
\mathrm{CH}_{3} \mathrm{COCH}_{3}+2 \mathrm{SbCl}_{3} \rightarrow \mathrm{Sb}_{2}\left(\mathrm{CH}_{3} \mathrm{COCH}_{3}\right)^{3+}+3 \mathrm{Cl}_{2} \\
\mathrm{Sb}_{2}\left(\mathrm{CH}_{3} \mathrm{COCH}_{3}\right)^{3+} \rightarrow 2 \mathrm{Sb}^{3+}+\mathrm{CH}_{3} \mathrm{COCH}_{3}
\end{gathered}
$$

Sulphur ions were derived from sodium thiosulphate as follows [15]:

$$
\begin{gathered}
\mathrm{Na}_{2} \mathrm{~S}_{2} \mathrm{O}_{3} \rightarrow 2 \mathrm{Na}^{+}+\mathrm{S}_{2} \mathrm{O}_{3}{ }^{2-} \\
6 \mathrm{~S}_{2} \mathrm{O}_{3}{ }^{2-} \rightarrow 3 \mathrm{~S}_{4} \mathrm{O}_{6}{ }^{2-}+6 \mathrm{e}^{-} \\
3 \mathrm{~S}_{2} \mathrm{O}_{3}{ }^{2-}+3 \mathrm{H}^{+} \rightarrow 3 \mathrm{HSO}_{3}+3 \mathrm{~S} \\
3 \mathrm{~S}+6 \mathrm{e}^{-} \rightarrow 3 \mathrm{~S}^{2-}
\end{gathered}
$$

Also copper ions were derived from copper chloride as follows:

$$
\mathrm{CuCl}_{2} \rightarrow \mathrm{Cu}^{2+}+2 \mathrm{Cl}^{-}
$$

There was adsorption of $\mathrm{Sb}_{2}\left(\mathrm{CH}_{3} \mathrm{COCH}_{3}\right)^{3+}$ complex on the surface of the glass substrate where ionic exchange with $\mathrm{Cu}^{2+}$ and $\mathrm{S}^{2-}$ resulted in a nucleation that gradually grew into the continuous $\mathrm{CuSbS}_{2}$ crystal.

Shortly after deposition, both films $33 \mathrm{G}$ and $33 \mathrm{H}$ were annealed in turn in an OMRON resettable thermostatic blast oven of range $50-1000^{\circ} \mathrm{C}$ for an hour in turn at temperature of $250^{\circ} \mathrm{C}$. This was to enhance better crystal order and deoxygenate the thin films. They were subsequently characterized for their optical and electrical properties. The optical absorbance of the films was taken using a UnicoUV-2102PC spectrophotometer at normal incident of light in the wavelength range of $200-1100 \mathrm{~nm}$ which spreads the NIR-VIS-UV region of the electromagnetic spectrum. From this absorbance $A$, the transmittance $T$, reflectance $R$, refractive index $\mathrm{n}$, extinction coefficient $\mathrm{k}$, real dielectrics constants $\varepsilon_{\mathrm{r}}$ as well as imaginary $\varepsilon_{\mathrm{i}}$ and optical conductivity $\sigma$ were deduced knowing their well known mathematical relationships:

$$
\mathrm{A}+\mathrm{T}+\mathrm{R}=1
$$

Transmittance,

$$
\mathrm{T}=10^{-\mathrm{A}}
$$

The absorption coefficient of the films, $\alpha$ is related to the transmittance $\mathrm{T}$ (with minor correction) [16] as:

$$
\alpha=\operatorname{Ln} \frac{1}{T}
$$

and $\alpha$ is used to decipher the band gap, Eg of the semiconducting TF knowing that in a semiconductor, electronic transition between bands are photon induced and are either direct or indirect according to the value of $n$ in the general Tauc's relationship between Eg and photon energy hv $[17,18]$ :

$$
\alpha h v=B(h v-E g)^{\mathrm{n} / 2}
$$

where $\mathrm{B}$ is a constant. For allowed transition as in the ternary sulphide considered, $\mathrm{n}=1$ and

$$
(\alpha h v)^{2}=\mathrm{A}(\mathrm{h} v-\mathrm{Eg})
$$

where $\mathrm{A}=\mathrm{B}^{2}$ is a constant. Hence a graph of $(\alpha \mathrm{h} v)^{2}$ against hv is linear with intercept on the hv axis as Eg.

Reflectance is related to TF refractive index $\mathrm{n}$ and extinction coefficient $\mathrm{k}$ as $[19,20]$ :

$$
\mathrm{R}=\frac{(\mathrm{n}-1)^{2}+\mathrm{k}^{2}}{(\mathrm{n}+1)^{2}+\mathrm{k}^{2}}
$$

If $\mathrm{k}^{2} \ll(\mathrm{n}-1)^{2}$ as is the case of semiconductors and insulators:

$$
R=\frac{(n-1)^{2}}{(n+1)^{2}}
$$

Hence,

$$
\mathrm{n}=\frac{(1+\mathrm{R})^{1 / 2}}{(1-\mathrm{R})^{1 / 2}}
$$

The extinction coefficient $\mathrm{k}$ is deduced using the wellknown equation [16]:

$$
\mathrm{k}=\frac{\alpha \lambda}{4 \pi}
$$

where $\mathrm{n}$ and $\mathrm{k}$ are used to describe the dielectric properties of TF as $\varepsilon=\varepsilon_{\mathrm{r}}+\varepsilon_{\mathrm{i}}$ where $\varepsilon_{\mathrm{r}}$ is the real part while $\varepsilon_{\mathrm{i}}$ is the imaginary part. Note that: 


$$
\varepsilon=(\mathrm{n}+\mathrm{ik})^{2}=\mathrm{n}^{2}-\mathrm{k}^{2}+2 \mathrm{ik}
$$

Hence,

$$
\varepsilon_{\mathrm{r}}=\mathrm{n}^{2}-\mathrm{k}^{2} \text { and } \varepsilon_{\mathrm{i}}=2 \mathrm{ki}
$$

The composition and thicknesses of the films were determined using Rutherford backscattering (RBS) technique. The electrical resistivity and sheet resistivity of thin films were measured using four point probe technique with a Quadpro, Model 301 auto calculating probe.

\section{Results and Discussion}

\subsection{Optical Results}

The optical absorbance, A for the $\mathrm{CuSbS}_{2} \mathrm{TFs}$ were as given in Figure 1 while the spectral transmittance $\mathrm{T}$, reflectance $\mathrm{R}$, refractive index $\mathrm{n}$, extinction coefficient $\mathrm{k}$, absorption coefficient $\alpha, \alpha^{2}$, real dielectric constant $\varepsilon_{\mathrm{r}}$ and imaginary dielectric constant $\varepsilon_{\mathrm{i}}$ were as presented in Figures $2,3,4,5,6,7,8$ and 9 respectively. There were no differences in absorbance of TF $33 \mathrm{G}$ and $33 \mathrm{H}$ in the ultra violet (UV) ranges of frequencies, but remarkable differences emerged as frequencies decreased to the Visible (VIS) and infra red (IR) ranges with PVA-medium TF having smaller absorbance (0.17) than the water-medium TF $(0.24)$.

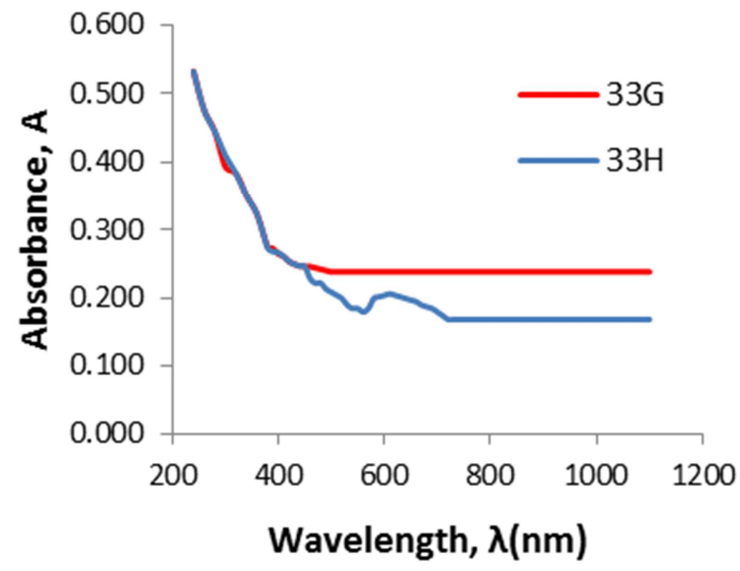

Figure 1. Spectral Absorbance of TF of $\mathrm{CuSbS}_{2}$.

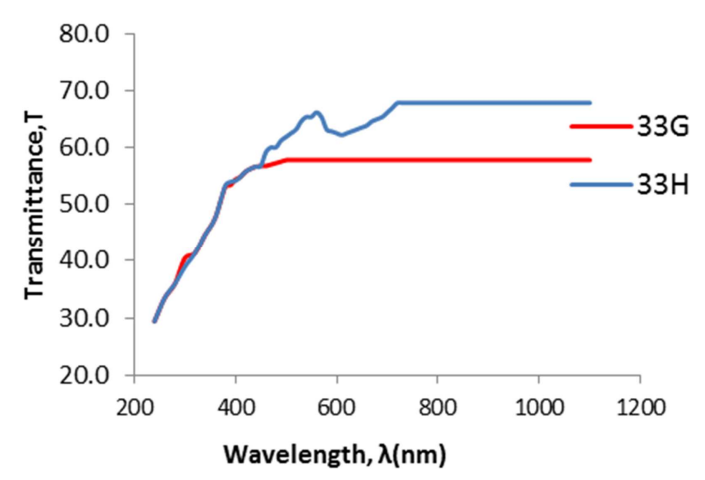

Figure 2. Spectral Transmittance of $\mathrm{CuSbS} \mathrm{S}_{2}$.

The trend for the transmittance (Figure 2) is the same but with film grown in water medium being smaller (15.3\%) in the VIS and IR region than the PVA-based film that was $18.4 \%$. A similar comparison between water-based and PVAbased $\mathrm{CuSbS}_{2}$ thin films regarding reflectance is graphically represented in Figure 3. It could be seen that growth medium had seriously affected the values of TF refractive index (Figure 4) and extinction coefficient (Figure 5) but only in the photon energy below $2.52 \mathrm{eV}$.

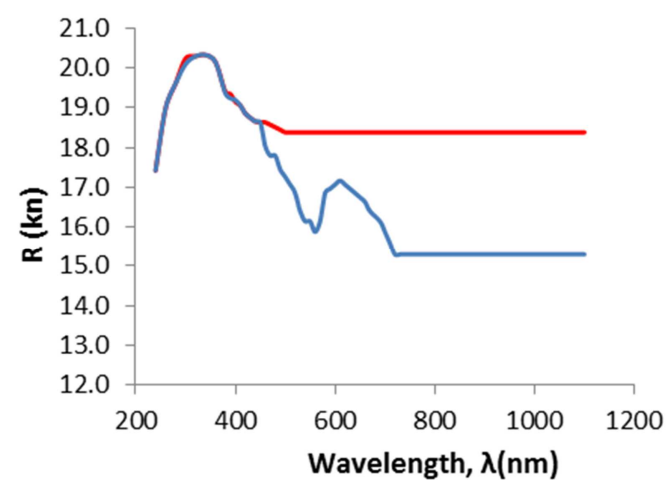

Figure 3. Spectral Reflectance of Thin Films of $\mathrm{CuSbS}_{2}$ for $33 \mathrm{G}$ (red) and $33 \mathrm{H}$ (blue).

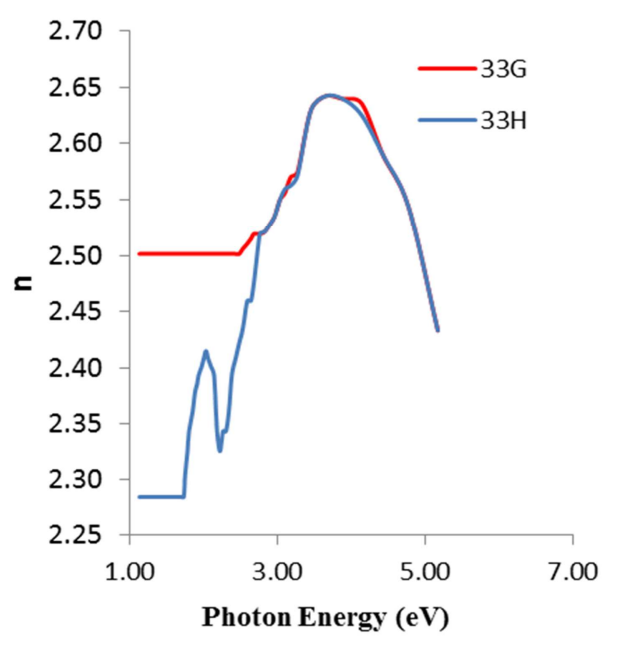

Figure 4. Refractive index of TFs.

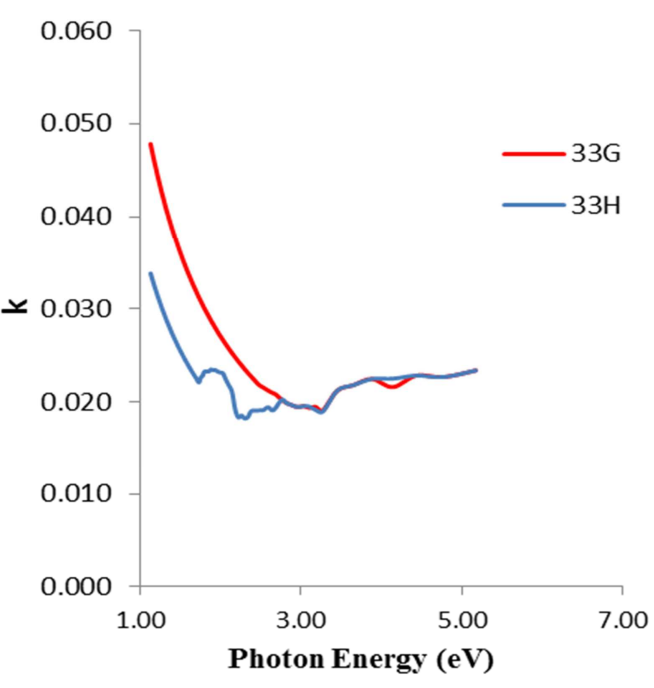

Figure 5. Extinction coefficient of TFs. 


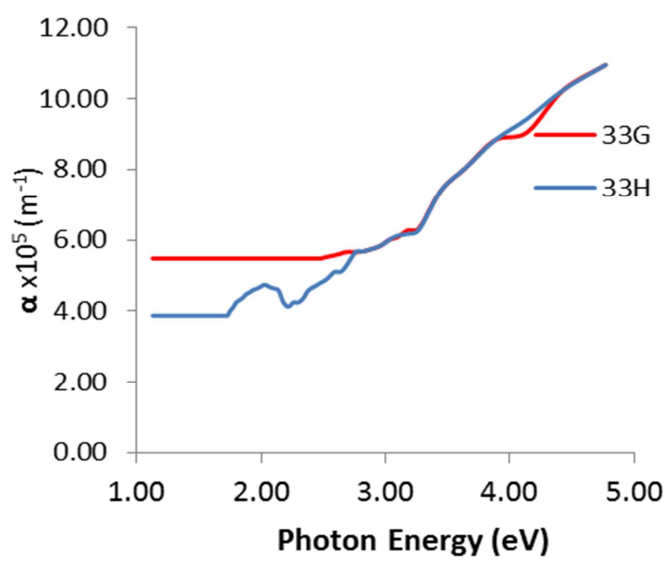

Figure 6. Absorption coefficient of Thin Films of $\mathrm{CuSbS} \mathrm{S}_{2}$

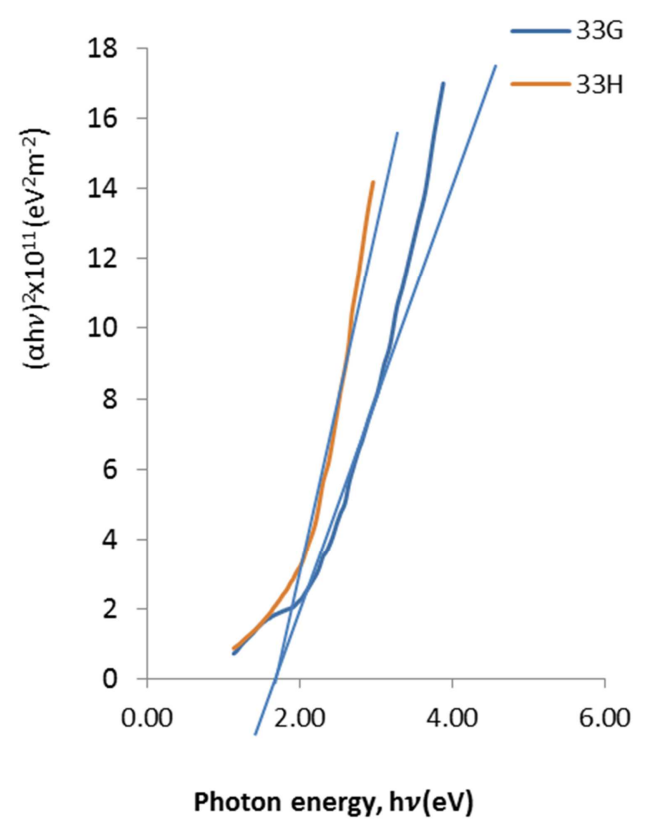

Figure 7. $(\alpha h v)^{2}$ versus photon energy for Thin Films of $\mathrm{CuSbS} \mathrm{S}_{2}$.

In a plot of $(\alpha h v)^{2}$ versus photon energy, hv, Tauc's relation (equ. 5) was utilized to decipher the thin film band gap as the intercepts of the projected linear potions of the graphs on the horizontal axis. These deduced band gaps (Figure 7) were however the same $1.74 \mathrm{eV}$ for both films $33 \mathrm{G}$ and $33 \mathrm{H}$. This is fairly in agreement with the values obtained in other similar researches [14, 21] involving copper antimony sulphide. The dielectric constants, ie real part $\varepsilon_{\mathrm{r}}$, and imaginary part $\varepsilon_{\mathrm{i}}$ of films are as presented in Figures 8 and 9 respectively while the optical conductivity variation of films $\sigma$ is presented in Figure 10. The medium of growth, as seen in Figures 8 and 9 was significant in the near infra red up till the visible region $(2.5 \mathrm{eV})$ while values of dielectric constants remain independent of growth media from the visible to higher energy UV waves. The optical conductivity of thin film grown in water medium was at least twice that grown in PVA medium in all frequencies considered and this disparity increased with higher energies of waves considered.

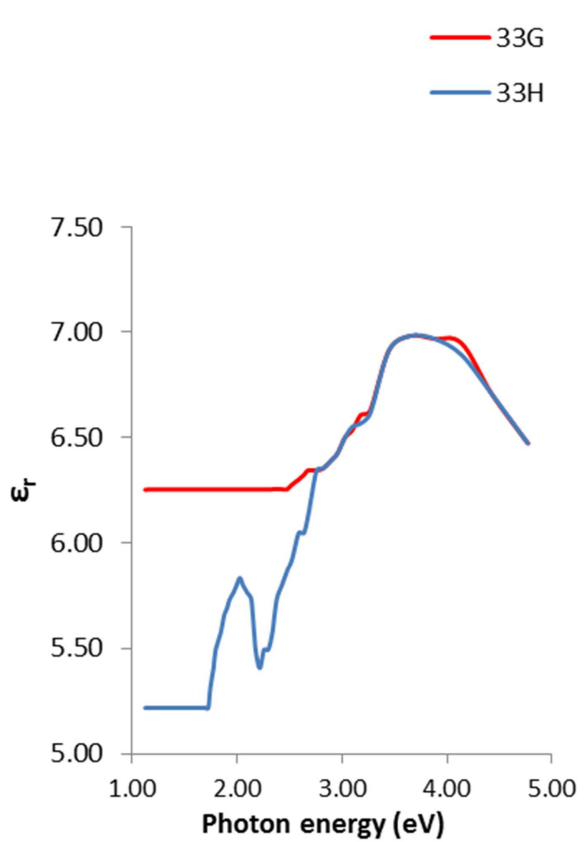

Figure 8. Real dielectric constant of TFs.

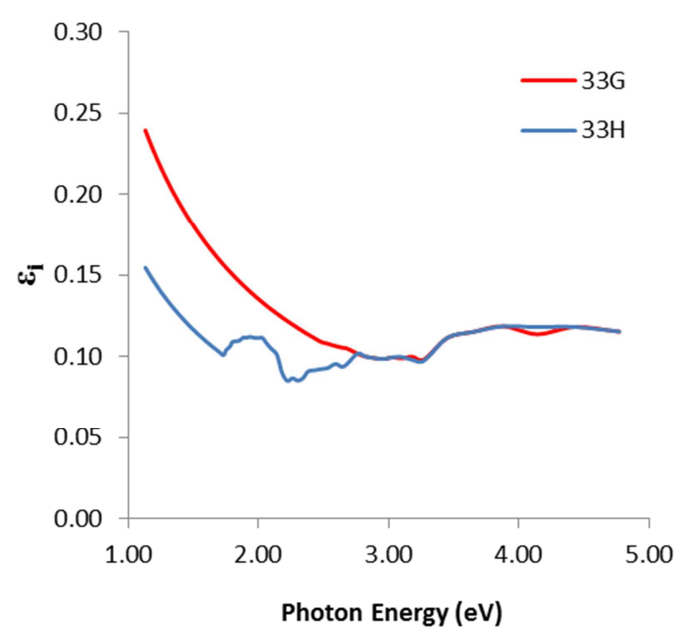

Figure 9. Imaginary dielectric constant versus photon energy $\mathrm{CuSbS}_{2}$

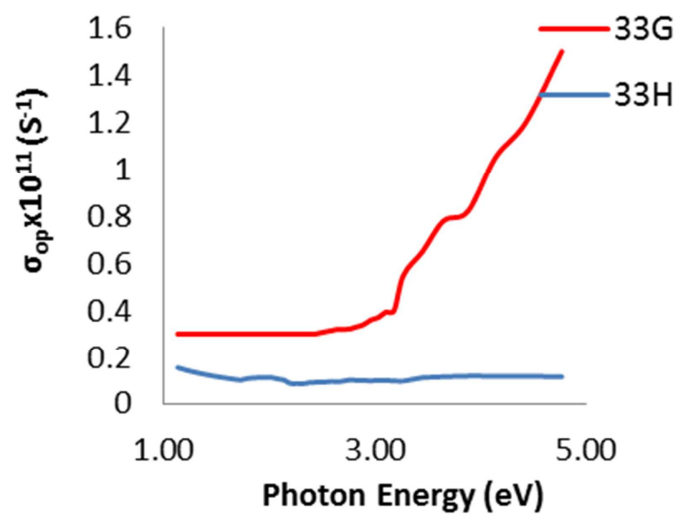

Figure 10. Optical conductivity of $\mathrm{CuSbS} \mathrm{S}_{2} \mathrm{TFs}$.

\subsection{Thickness and Electrical Properties Results}

The thicknesses of thin films as measured in Rutherford backscattering technique and the resistivity of films as measured 
with four point probe technique are given in Table 1. Thicknesses were of nano sizes and with PVA-based film thinner than the water-based. The early formation of crystallites in the pores of polymer PVA enabled a quick and fairly ordered crystal in film $33 \mathrm{H}$. This orderliness clearly evidenced in a similar work by one of us [14] on the study of growth media effects on the solid state properties of same ternary thin films.

Table 1. Thicknesses and Electrical Properties of Thin Films Grown in Water (33G) and in PVA (33H) Media.

\begin{tabular}{lllll}
\hline TFs & $\begin{array}{l}\text { Thickness } \\
(\mathbf{n m})\end{array}$ & $\begin{array}{l}\text { Sheet resistance } \\
\mathbf{R s x 1 0} \mathbf{(} \mathbf{( s q})\end{array}$ & $\begin{array}{l}\text { Resistivity } \\
\boldsymbol{\rho}(\boldsymbol{\Omega m})\end{array}$ & $\begin{array}{l}\text { Conductivity } \\
\left(\mathbf{\Omega}^{-1} \mathbf{m}^{-\mathbf{1}}\right)\end{array}$ \\
\hline $33 \mathrm{G}$ & 545 & 14.12 & 770 & 0.0013 \\
$33 \mathrm{H}$ & 514 & 13.58 & 699 & 0.0011 \\
\hline
\end{tabular}

\section{Conclusion}

In chemical bath deposition (CBD) technique, we have grown copper antimony sulphide thin films in water medium as well as in polyvinyl alcohol medium and compared the effects of such media on optical and electrical properties of the TFs. The study showed that TF optical properties varied with growth media from the near infra red to the middle of visible frequencies but remained fairly same in the middle visible and higher frequencies (of ultra violet). The electrical resistivities of both films were rather too close for meaningful deductions while the band gaps of the TFs remained same $(1.74 \mathrm{eV})$. The choice of the medium: water or PVA could therefore be useful to tailor optical parameters of $\mathrm{CuSbS}_{2}$ thin films only in the infra red range of radiation.

\section{References}

[1] L. Jae-Hyeong, S. Woo-Chang, Y. Jun- Sin, and Y. Yeong-Sik, "Synthesis and Characterization of $\mathrm{CuSbS}_{2}$, Effect of Medium," Solar Energy Material, vol. 75, pp. 227-234, 2003.

[2] M. T. S. Nair, Y. Pena, J. Campos, V. M. Garcia and P. K. Nair, " $\mathrm{Sb}_{2} \mathrm{~S}_{3}$ and $\mathrm{Sb}_{2} \mathrm{~S}_{3}$-CuS Thin Films," Journal of Electrochem. Soc., vol. 145, p. 2113, 1998.

[3] R. Suarez and P. K. Nair, "Chemical Bath Deposition of Thin Film PbS-CuS," Journal of Solid State Chemistry, vol. 123, no. 2, pp. 296-300, 1996.

[4] A. I. Onyia,"Effects of Deposition Medium on the Solid State Characteristics of Pb-Doped CdS Thin Films Fabricated in Chemical Bath Technique," International Journal of Science and Engineering Research, vol. 8, pp. 1420-1424, 2018.

[5] R. A. Chikwenze, "Solution Growth and Characterization of Binary Selenide Thin Films for Device Applications," Ph. D Thesis, UNN, Nigeria, 2012.

[6] X. Y. Tao, X. B. Zhang and J. H. Geise,“ Activated Carbon, Classifications, Properties and Applications," Carbon, vol. 44, no. 8, p. 1426, 2006.

[7] Z. S. Khalifa, "Grain Size Reduction on Nanostructured $\mathrm{TiO}_{2}$
Thin Films Due to Annealing," RSC. Adv., vol. 7, pp. 3029530302, 2017.

[8] M. Khojasteh, S. Haghighat, J. M. Dawlaty, and V. V. Kresin, "Controlled Deposition of Size- selected MnO Nanoparticle Thin Films for Water Splitting Applications: Reduction of Onset Potential With Particle Size," Nanotechnology, vol. 29, no. 21, p. 215603, 2018.

[9] M. M. El-Nahass, H. M. Zeyadu, N. A. El- Ghamaz, and A. E. Shetiwy, "Particle Size Reduction of Thalium Indium Sulphide, Eff ect of Annealing" Opik, vol. 171, p. 580, 2018,

[10] J. J. Wang, Y. Q. Wang, F. F. Cao, Y. G. Guo, and L. J. Wan, "Synthesis of Mono Dispersed Wurtzite Structure $\mathrm{CuInSe}_{2}$ Nanocrystals," J. Am. Chem. Soc., vol. 132, pp. 12218-12221, 20100.

[11] A. W. Welch, P. P. Zawadzki, S. Lany, C. A. Wolden, and A. Zakutayev, "Self-regulated Growth and Tunable Properties of $\mathrm{CuSbS}_{2}$ Solar Absorbers," Sol. Energy Mater. Sol. Cells, vol. 132, pp. 499-506, 2014.

[12] C. S. Liu, L. Chen, X. Niel, and R. Yuan, "The Influence of Substrate Temperature on Spray- Deposited $\mathrm{CuSbS}_{2}$ Thin Films," Chalcogenide Letters, vol. 11, no. 12, pp. 639- 644, 2014.

[13] Y. Rodriguez-Lazcano, M. T. S. Nair, and P. K. Nair, "CuSbS Thin Film Formed Through Chemically Deposited $\mathrm{Sb}_{2} \mathrm{~S}_{3}-\mathrm{CuS}$ Thin Films," Journal of Crystal Growth, vol. 223, p. 399, 2001.

[14] A. I. Onyia, "Study of the Differences in Solid State Properties of Copper Antimony Sulphide Thin Films Grown in Two Different Media," IJSAR Journal of Engineering and Computing (IJSAR-JEC), vol. 5, pp. 43-51, March/June 2019.

[15] J. C. Osuwa and R. U. Osuji (2011). "Analysis of Electrical and Microstructural Properties of Annealed Antimony Sulphide $\left(\mathrm{Sb}_{2} \mathrm{~S}_{3}\right)$ Thin Films," Chalcogenide Letters, vol. 8, no. 9, pp. 571-57, 2011.

[16] I. J. Pankove, Optical Processes in Semiconductors, New Jersey: Prentice Hall Inc., p. 88, 1971.

[17] F. Haque, K. S. Rahman, M. A. Islam, K. Sopian, and N. Amin,. "Growth Optimization in $\mathrm{ZnS}$ Thin Films by rf Magnetron Sputtering as Prospective Buffer layer in Thin Film Solar Cells," Chalcogenide Letters, vol. 11, no. 4, pp. 189-197, 2014.

[18] C. A. R. Maria Sahayara, A. Mohan, V. Arivazhagan, and S. Rajash, "Investigation on Structural and Optical Properties of Thermally Evaporated SnSe Thin Film," Chalcogenide Letters, vol. 11, no. 2, pp. 47-52. 2014.

[19] K. L. Chopra, and S. R. Das, Thin Film Solar Cells. New York, NY: Plenum Press, p. 7, 1986.

[20] A, O. E. Animalu, Intermediate Quantum Theory of Crystalline Solids, New Jersey: Prentice-Hall Inc., p. 225, 1977.

[21] S. C. Ezugwu, F. I. Ezema, and P. U. Asogwa, "Synthesis and Characterization of Ternary $\mathrm{CuSbS}_{2}$ Thin Films: Effect of Deposition Time," Chalcogenide Letters, vol. 7, no. 5, pp. 341-348, 2010. 